Extended Abstract

\title{
Agents, Patients and Robots. About Roboethics
}

\author{
Rafael Capurro \\ International Center for Information Ethics (ICIE), Redtenbacherstrasse 9, 76133 Karlsruhe, Germany \\ E-Mail: rafael@capurro.de; Tel: +49-721-9822922; Fax: +49-721-9822921
}

Accepted: 27 March 2015

The purpose of this paper is to address some of the questions on the notion of agent and agency in relation to property and personhood. I argue that following the Kantian criticism of Aristotelian metaphysics, contemporary biotechnology and information and communication technologies bring about a new challenge - this time, with regard to the Kantian moral subject understood in the subject's unique metaphysical qualities of dignity and autonomy. The concept of human dignity underlies the foundation of many democratic systems, particularly in Europe as well as of international treaties, including the Universal Declaration of Human Rights. Digital agents, artificial organisms as well as new capabilities environments bring about an important transformation of the human self-appraisal. A critical comparative reflection of this transformation is important because of its ethical implications. I deal first with the concept of agent within the framework of Aristotelian philosophy, which is the basis for further theories in accordance with and/or in opposition to it, particularly since modernity. In the second part of this paper, I deal with the concept of personhood in Kantian philosophy, which supersedes the Aristotelian metaphysics of substance and builds the basis of a metaphysics of the moral human subject. In the third part, I discuss the question of artificial agents arising from modern biology and ICT. Blurring the difference between the human and the natural and/or artificial opens a "new space" for philosophical reflection as well as for debate in law and practical policy.

(C) 2015 by the authors; licensee MDPI and ISIS. This abstract is distributed under the terms and conditions of the Creative Commons Attribution license. 